ARTICLE

Received 1 Aug 2015 | Accepted 3 Aug 2016 | Published 9 Sep 2016

DOI: $10.1038 /$ ncomms12809

OPEN

\title{
Plasmonic twinned silver nanoparticles with molecular precision
}

Huayan Yang ${ }^{1, \star}$, Yu Wang ${ }^{1, \star}$, Xi Chen ${ }^{2}$, Xiaojing Zhao ${ }^{1}$, Lin Gu ${ }^{3}$, Huaqi Huang ${ }^{1}$ Juanzhu Yan ${ }^{1}$, Chaofa Xu1, Gang $\mathrm{Li}^{4}$, Junchao $\mathrm{Wu}^{5}$, Alison J. Edwards ${ }^{6}$, Birger Dittrich ${ }^{7}$, Zichao Tang ${ }^{1,4}$, Dongdong Wang ${ }^{5}$, Lauri Lehtovaara ${ }^{2}$, Hannu Häkkinen ${ }^{2,8} \&$ Nanfeng Zheng ${ }^{1}$

Determining the structures of nanoparticles at atomic resolution is vital to understand their structure-property correlations. Large metal nanoparticles with core diameter beyond $2 \mathrm{~nm}$ have, to date, eluded characterization by single-crystal X-ray analysis. Here we report the chemical syntheses and structures of two giant thiolated Ag nanoparticles containing 136 and $374 \mathrm{Ag}$ atoms (that is, up to $3 \mathrm{~nm}$ core diameter). As the largest thiolated metal nanoparticles crystallographically determined so far, these $\mathrm{Ag}$ nanoparticles enter the truly metallic regime with the emergence of surface plasmon resonance. As miniatures of fivefold twinned nanostructures, these structures demonstrate a subtle distortion within fivefold twinned nanostructures of face-centred cubic metals. The Ag nanoparticles reported in this work serve as excellent models to understand the detailed structure distortion within twinned metal nanostructures and also how silver nanoparticles can span from the molecular to the metallic regime.

\footnotetext{
${ }^{1}$ Collaborative Innovation Center of Chemistry for Energy Materials, State Key Laboratory for Physical Chemistry of Solid Surfaces, and Engineering Research Center for Nano-Preparation Technology of Fujian Province, College of Chemistry and Chemical Engineering, Xiamen University, 422 Siming South Road, Xiamen 361005, China. ${ }^{2}$ Nanoscience Center, Department of Chemistry, University of Jyväskylä, Box 35, 40014 Jyväskylä, Finland. ${ }^{3}$ Institute of Physics, Chinese Academy of Sciences, Beijing 100190, China. ${ }^{4}$ State Key Laboratory of Molecular Reaction Dynamics, Dalian Institute of Chemical Physics, Chinese Academy of Sciences, Dalian 116023, China. ${ }^{5}$ Department of Civil Engineering, Xiamen University, Xiamen, Fujian 361005, China. ${ }^{6}$ Australian Nuclear Science and Technology Organization, Australian Centre for Neutron Scattering, New Illawarra Road, Lucas Heights, New South Wales 2234 , Australia. ${ }^{7}$ Heinrich-Heine Universität Düsseldorf, Anorganische Chemie und Strukturchemie, Universitätsstrasse 1, Gebäude 26.42.01.21, 40225 Düsseldorf, Germany.

${ }^{8}$ Nanoscience Center, Department of Physics, University of Jyväskylä, Box 35, 40014 Jyväskylä, Finland. * These authors equally contributed to this work. Correspondence and requests for materials should be addressed to N.F.Z. (email: nfzheng@xmu.edu.cn) or to H.H. (email: hannu.j.hakkinen@jyu.fi) or to A.J.E. (email: aed@ansto.gov.au).
} 


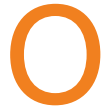

wing to quantum-size and surface effects, nanoparticles frequently exhibit novel physical and chemical properties, which differ from their bulk counterparts in dramatic ways, and they have been gaining increasing attention in the fundamental and applied sciences ${ }^{1-7}$. Properties of nanoparticles are governed by chemical composition, size, shape and the overall molecular structure ${ }^{1,2}$. Despite significant progress in the chemical fabrication of uniform functional nanoparticles with well-defined shapes, sizes and compositions over the past two decades $^{8-11}$, it is still notoriously difficult to manipulate their structures and thus functions with molecular control. Currently, there is the lack of effective tools to characterize the detailed structures (for instance, defects, twinning and surface features) of functional nanoparticles at atomic resolution. Without a detailed molecular structure as a guide, precision synthesis of nanoparticles with targeted functionality is difficult.

During the last several years, two major strategies have been applied in pursuit of detailed structure analysis of metal nanoparticles. One is application of state-of-the-art electron microscopy techniques to probe the atomic-resolution structures of the nanoparticle core ${ }^{12-17}$. Azubel et al. ${ }^{16}$ have reported the structure determination of a ligand-stabilized $\mathrm{Au}_{68}$ nanoparticle at atomic resolution by a combination of a low-dose approach and aberration-corrected transmission electron microscopy (TEM). The other avenue is to prepare and crystallize monodisperse metal nanoparticles into single crystals and determine their structures using X-ray diffraction ${ }^{18-31}$. Such an approach is particularly important to resolve the metal-ligand interfacial features at the metal nanoparticle surface. By this approach, the structures of a few ligand-stabilized (for instance, carbon monoxide and thiolate) metal nanoparticles containing over 100 metal atoms (for instance, $\mathrm{Au}_{102}, \mathrm{Au}_{133}$ and $\mathrm{Au}_{130}$ ) have been determined at or near atomic resolution ${ }^{18-21,32}$. Despite significant progress following both strategies, resolution of the molecular structure of metal nanoparticles containing several hundred metal atoms and having metallic properties remains daunting ${ }^{20,33}$.

We report here the syntheses and structure determinations of two giant, thiolated Ag nanoparticles containing 136 and $374 \mathrm{Ag}$ atoms. As the largest thiolated metal nanoparticles crystallographically determined so far, these Ag nanoparticles exhibit unprecedented metallic properties with the emergence of surface plasmon resonance (SPR). The nanoparticles are miniatures of two closely related fivefold twinned nanostructures, pentagonalbipyramidal (that is, decahedral) nanoparticles and twinned nanorods/nanowires derived from decahedral particles by elongation along the fivefold axis. Small distortions from the structure archetype within the fivefold twinned nanostructures are observed. Density functional theory (DFT) studies reveal that the smaller nanoparticle has molecular character with a small but distinct energy gap (band gap) between occupied and unoccupied orbitals (highest occupied molecular orbital-lowest unoccupied molecular orbital gap), whereas the larger one is fully metallic without a band gap. This leads to emergence of the surface plasmon incorporating contributions from the organic ligand layer. These two structurally determined systems represent important exemplars of the cross-over of Ag nanoparticles from the molecular to the metallic regime.

\section{Results}

Syntheses and TEM characterizations. The syntheses of thiolated Ag nanoparticles were achieved by chemical reduction of a polymeric silver 4-tert-butylbenzenethiolate precursor by $\mathrm{NaBH}_{4}$ in the presence of $\mathrm{PPh}_{4} \mathrm{Br}$ and triethylamine (see Methods for full details). The resulting Ag nanoparticles were first characterized by TEM as shown in Fig. 1a and Supplementary Fig. 1. The TEM images revealed that these thiolated Ag nanoparticles had a tight particle-size distribution at $\sim 2 \mathrm{~nm}$. Thiolated Ag nanoparticles of larger, likewise uniform size, at $\sim 3 \mathrm{~nm}$ (Fig. $1 \mathrm{~b}$ and Supplementary Fig. 2) were prepared in a similar manner, by increasing the Ag:SR (thiolate) molar ratio to $1.4: 1$.

Two important features are associated with these thiolated Ag nanoparticles. First, their sizes lie in the region where metallic Ag nanoparticles are said to develop $\mathrm{SPR}^{34}$ and thus provide scope to assess the occurrence of SPR from the viewpoint of associated quantum mechanical calculations. Second, the small and large Ag nanoparticles are verified as fivefold twinned nanocrystals as initially revealed by high-resolution TEM analysis (insets in Fig. 1 and Supplementary Figs 3 and 4). Fivefold twinning is a common phenomenon for nanoparticles of face-centred cubic (fcc) metals ${ }^{9}$. Competing models for the internal structure of fivefold twinned nanoparticles have been debated in the literature ${ }^{35,36}$ Resolving these atomic scale structures now demonstrates at the molecular level how the lattice mismatches are readily resolved within real fivefold twinned nanoparticles.

Molecular structures from single-crystal X-ray diffraction. Encouraged by the uniform size of both the small and large thiolated Ag nanoparticles, crystallization of these compounds was undertaken. High-quality black prism crystals of small nanoparticles and block crystals of large nanoparticles that

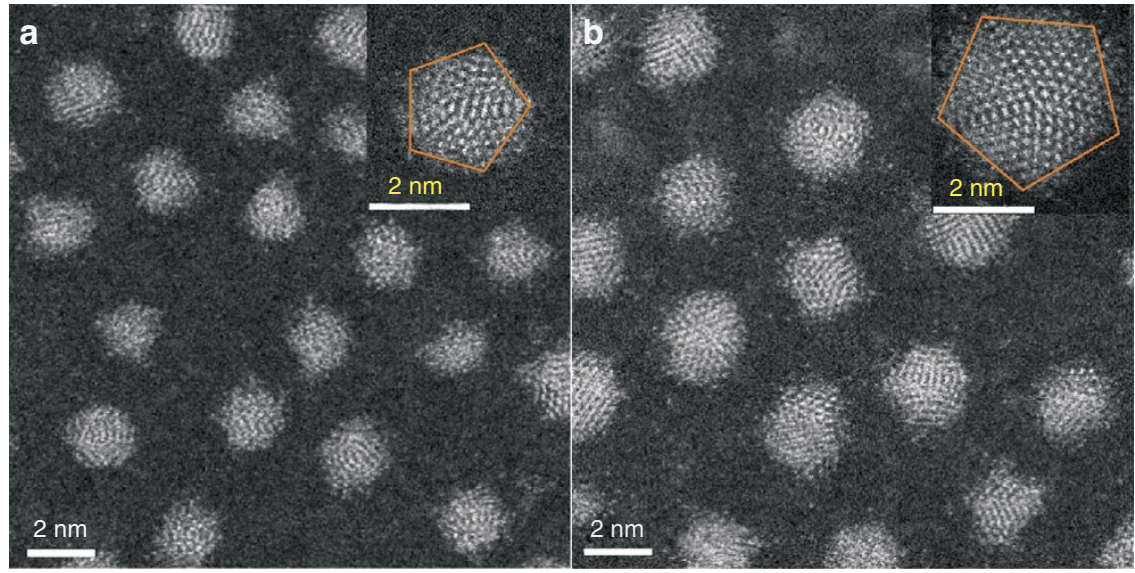

Figure 1 | Electron micrographs of thiolated Ag nanoparticles. Scanning TEM and high-resolution TEM (inset) images of the as-prepared small (a) and large (b) 4-tert-butylbenzenethiolate-stabilized Ag nanoparticles. Scale bars, $2 \mathrm{~nm}$. 


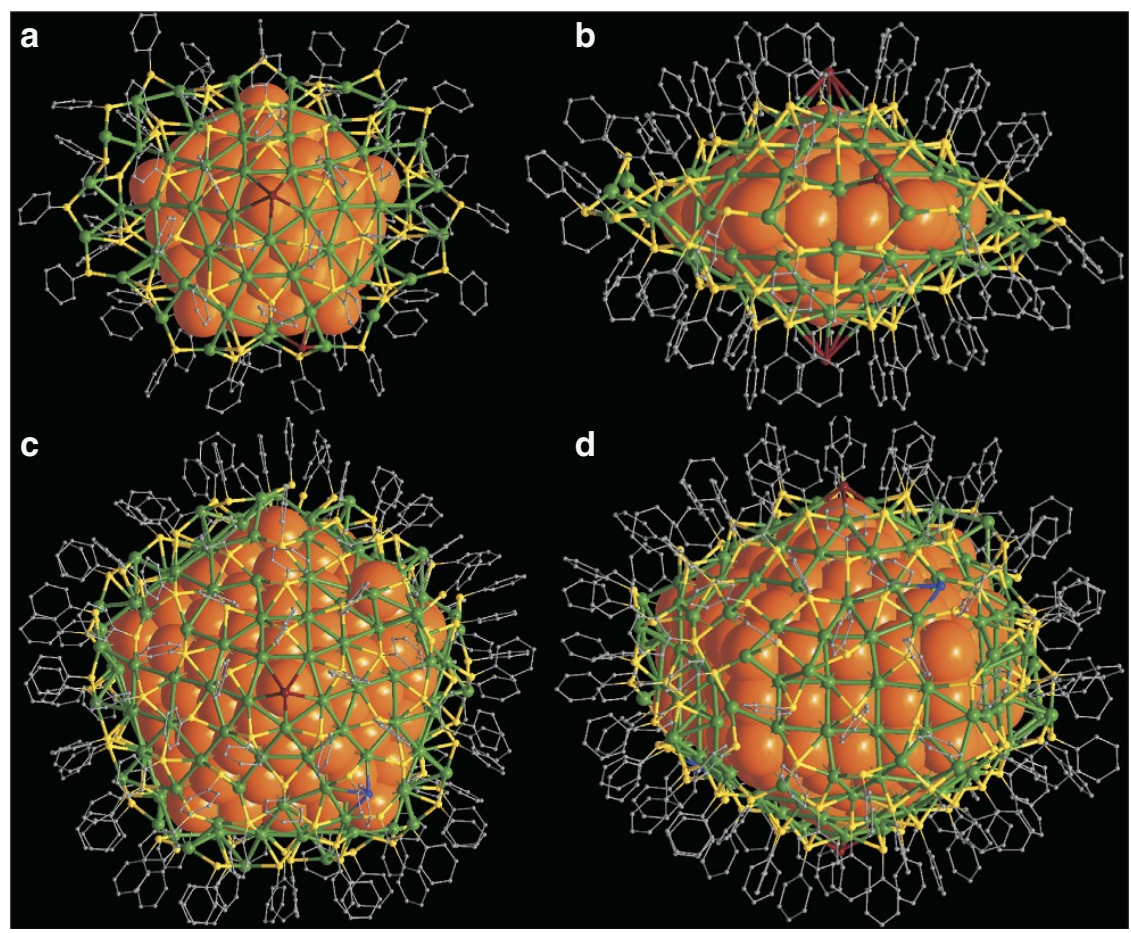

Figure 2 | The overall structures of $\mathbf{A g}_{\mathbf{1 3 6}}$ and $\mathbf{A g}_{\mathbf{3 7 4}}$ nanoparticles. (a,b) Top and side views of $\left[\mathrm{Ag}_{136}\left(\mathrm{SR}_{64} \mathrm{Cl}_{3} \mathrm{Ag}_{0.45}\right]^{-}\right.$. (c, d) Top and side views of $\left[\mathrm{Ag}_{374}(\mathrm{SR})_{113} \mathrm{Br}_{2} \mathrm{Cl}_{2}\right]$. Colour legend: orange, core $\mathrm{Ag}$; green, surface $\mathrm{Ag}$; yellow, S; brown, halogen; blue, $\mathrm{Cl}$; grey, $\mathrm{C}$. All hydrogen atoms and tert-butyl groups are omitted for clarity.

were suitable for X-ray analysis were obtained by diffusion of hexane into their dichloromethane solutions (Supplementary Fig. 5). The fivefold twinned feature of both small and large silver nanoparticles was indeed revealed by detailed single crystal X-ray diffraction studies (for $1.2 \AA$ resolution data in each case; Supplementary Data 1 and 2). Initial structure solutions were acquired by means of SHELXL ${ }^{37}$ and model refinements combined techniques of macromolecular crystallography with those more typical of chemical crystallography (Supplementary Methods and Supplementary Tables 1 and 2). ${ }^{38-42}$ As shown in Fig. 2, the small nanoparticle has a composition modelled as $\left[\mathrm{Ag}_{136}(\mathrm{SR})_{64} \mathrm{Cl}_{3} \mathrm{Ag}_{0.45}\right]^{-}$(denoted as $\mathrm{Ag}_{136}$ ) with the apparent mono-anionic charge balanced by a well-resolved $\mathrm{PPh}_{4}^{+}$and one entire nanoparticle plus cation pair forming the asymmetric unit. The larger nanoparticle has a composition modelled as $\left[\mathrm{Ag}_{374}(\mathrm{SR})_{113} \mathrm{Br}_{2} \mathrm{Cl}_{2}\right]$ (denoted as $\mathrm{Ag}_{374}$ ) with one half molecule lying on a crystallographic twofold axis comprising the asymmetric unit (Supplementary Figs 6 and 7). SR in both cases is 4-tert-butylthiophenolate. The presence of $\mathrm{Cl}$ in $\mathrm{Ag}_{136}$, and both $\mathrm{Cl}$ and $\mathrm{Br}$ in $\mathrm{Ag}_{374}$ were confirmed by temperatureprogrammed decomposition/mass-spectrometric and electrospray ionization mass-spectrometric data (Supplementary Fig. 8). $\mathrm{Ag}_{136}$ and $\mathrm{Ag}_{374}$ represent the largest thiolated metal nanoparticles with molecular structures determined by singlecrystal X-ray analysis. They bear no structural relationship to a previously reported series of thiolated $\mathrm{Ag}_{x} \mathrm{~S}_{y}$ particles containing up to $490 \mathrm{Ag}$ atoms, derived from bulk $\mathrm{Ag}_{2} \mathrm{~S}$ semiconducting materials ${ }^{43,44}$.

Both $\mathrm{Ag}_{136}$ and $\mathrm{Ag}_{374}$ can be structurally described as a fivefold twinned core enclosed within related structurally distinctive $\mathrm{Ag}-\mathrm{SR}$ complex shells (Fig. 2). While the fivefold twinned core in $\mathrm{Ag}_{136}$ is present as a pentagonal bipyramid of $54 \mathrm{Ag}$ atoms, the core in $\mathrm{Ag}_{374}$ is an elongated pentagonal bipyramid (Ino's decahedron) consisting of $207 \mathrm{Ag}$ atoms. The $\mathrm{Ag}_{54}$ core in $\mathrm{Ag}_{136}$ can be structurally described as five conjoined tetrahedral domains of fcc $\mathrm{Ag}$ (Fig. 3a), each of which consists of $20 \mathrm{Ag}$ atoms (Fig. 3b) and having 4 external $\mathrm{Ag}\{111\}$ facets. Each tetrahedral subunit is joined to the adjacent tetrahedral subunits by sharing of common triangular faces. In comparison, the $\mathrm{Ag}_{207}$ core of $\mathrm{Ag}_{374}$ can be considered as a miniature fivefold twinned nanorod constructed from five conjoined single-crystalline wedge-shaped grains, which are related to the pentagonalbipyramid by elongation of each constituent tetrahedron to a wedge along the molecular fivefold aspect (Fig. 3c). In each wedge-shaped grain, there are two (111) triangular faces at the apices, two (111) trapezoids with their long edge on the fivefold axis and one (100) rectangle forming each side (Fig. 3d). Overall, each nanorod has five (100) side surfaces parallel to the elongated direction and ten (111) surfaces at the apices of the rod. The 207 $\mathrm{Ag}$ atoms in the core are distributed about a central $\mathrm{Ag}$ atom successively surrounded by three elongated pentagonal bipyramids consisting of 12,42 and 92 atoms, encircled by a 'pentagonal cylinder' of $60 \mathrm{Ag}$ atoms likewise centred about the fivefold axis of the nanorod (Supplementary Fig. 9). The metal distributions in the cores of both $\mathrm{Ag}_{136}$ and $\mathrm{Ag}_{374}$ are entirely distinct from that in $\mathrm{Au}_{133}$ whose structure was reported (after submission of this report) to have a 20 -fold twinned icosahedral core ${ }^{20,21}$. It should be noted that fivefold twinned metal cores have also been previously observed in $\mathrm{Au}_{102}$ and $\mathrm{Au}_{130}$ clusters resolved by single-crystal $\mathrm{X}$-ray analysis ${ }^{19,32}$ and $\mathrm{Au}_{309}$ characterized by aberration-corrected scanning TEM ${ }^{13}$.

Structural distortions inside fivefold twinned cores. In regular fcc metals, the idealized angle between two (111) faces is $70.53^{\circ}$. When joined together by sharing (111) faces along the fivefold axis, without distortion, five ideal single-crystalline grains in a fivefold twinned nanostructure can only subtend an angle of $352.65^{\circ}, 7.35^{\circ}$ short of closure (Supplementary Fig. 10) $)^{17,45}$. In a real fivefold twinned nanostructure, this solid-angle deficiency needs to be compensated by sufficiently adjusting the interatomic spacings, introduction of various defects such as dislocations and 
a

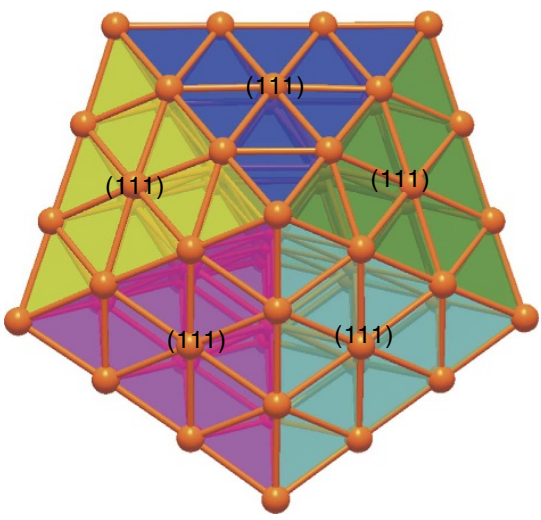

C

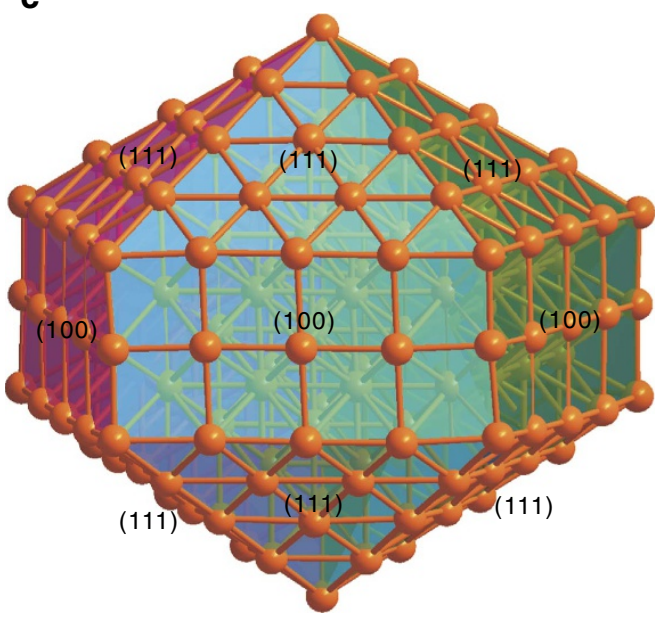

b

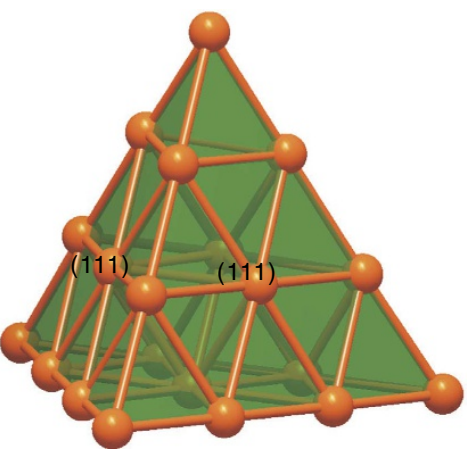

d

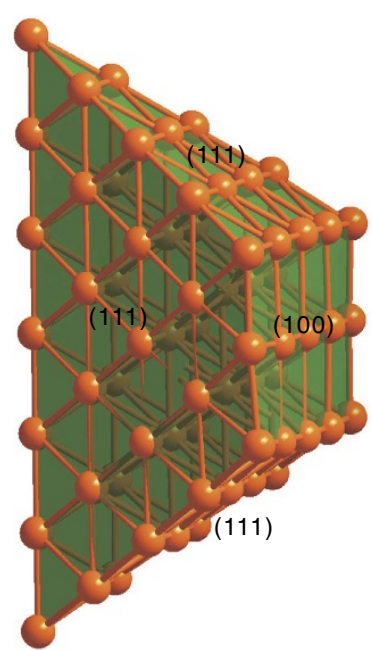

Figure 3 | The structure dissection of the fivefold twinned cores of $\mathbf{A g}_{\mathbf{1 3 6}}$ and $\mathbf{A g}_{\mathbf{3 7 4}}$ nanoparticles. (a) Core of $\mathrm{Ag}_{136}$, consisting of five tetrahedral units (b). (c) Core of $\mathrm{Ag}_{374}$, consisting of five wedge-shaped units (d). Different colours are used to highlight the five different twinning domains of the cores.

stacking faults, or by increased internal vibrations. Structural models with homogeneous or inhomogeneous strain (deviations from idealized values) have been proposed for small metal nanoparticles 35,36 . In the fivefold twinned cores of $\mathrm{Ag}_{136}$ and $\mathrm{Ag}_{374}$, the average $\mathrm{Ag}-\mathrm{Ag}$ bond lengths are 2.870 and $2.882 \AA$, respectively, both slightly shorter than the $\mathrm{Ag}-\mathrm{Ag}$ bond distance $(2.889 \AA)$ of bulk silver with $\mathrm{Ag}_{374}$ only marginally so.

Detailed review of the $\mathrm{Ag}-\mathrm{Ag}$ bond lengths (Supplementary Fig. 11) demonstrates the presence of a distinctive distortion within the observed pentagonal bipyramidal $\mathrm{Ag}_{54}$ core, where an obvious anisotropy of these adjustments is clear. Although Ag-Ag distances (18 out of 23) parallel to the fivefold axis are shorter than the average $\mathrm{Ag}-\mathrm{Ag}$ distance $(2.870 \AA \mathrm{A})$, most $\mathrm{Ag}-\mathrm{Ag}$ bonds (47 out of 50) perpendicular to the fivefold axis are longer than $2.870 \AA$. Such a distribution clearly suggests that the geometric non-ideality in the decahedral core is resolved via a modest compression along the fivefold axis and concomitant relaxation about the directions perpendicular to the fivefold axis. In other words, each tetrahedral grain in the fivefold twinned decahedral nanoparticle is slightly compressed along the molecular fivefold axis. In $\mathrm{Ag}_{136}$, the five relevant angles are $71.5,71.7,72.1,72.3$ and $72.5^{\circ}$, slightly expanded from the idealized $70.53^{\circ}$ by $1^{\circ}-2^{\circ}$. These small deviations eliminate the $7.35^{\circ}$ deficiency. Geometrically, this slight anisotropy evidently minimizes the total potential energy of the silver core (Supplementary Figs 12-14). In contrast to the anisotropy observed in the $\mathrm{Ag}_{54}$ core, no obvious trends are seen in the $\mathrm{Ag}_{207}$ core. Small deviations from planarity (a slight bulging) at the twinning boundaries appears to be the only readily discernible compensation for the solid-angle deficiency of the fivefold twinned $\mathrm{Ag}_{207}$ core. Careful analysis reveals that the fivefold twinning boundary (111) faces in the $\mathrm{Ag}_{207}$ core are not strictly planar (Supplementary Fig. 15). Within each shared (111) face, some Ag atoms deviate from the plane of their coplanar Ag set by up to $0.20 \AA$.

Surface structures. Based on TEM measurements, many studies have concluded that a decahedral nanoparticle should be bound by ten (111) facets and a fivefold twinned nanorod/nanowire of metals should have five (100) faces at its side and ten (111) faces, five at either end ${ }^{9}$. The X-ray studies of $\mathrm{Ag}_{136}$ and $\mathrm{Ag}_{374}$ validate this hypothesis for their $\mathrm{Ag}_{54}$ and $\mathrm{Ag}_{207}$ cores. However, the crystallographic studies reveal that the thiolate capped outermost $\mathrm{Ag}$ atoms deviate from the close-packed archetypes in a significant manner but with a marked congruence of the deviations from close packing observed in the two structures. In $\mathrm{Ag}_{136}$, the $\mathrm{Ag}_{54}$ core comprises two pentagonal pyramids, each of which is surmounted by a bowl-like $\left[\mathrm{Ag}_{30}(\mathrm{SR})_{15} \mathrm{Cl}\right]$ unit (Fig. 4a). The silver atoms in $\left[\mathrm{Ag}_{30}(\mathrm{SR})_{15} \mathrm{Cl}\right]$ describe one half of a parabigyrate rhombicosidodecahedron (Johnson solid J73-a circumscribable 60 vertex figure). These 30 silver atoms lie with their fivefold aspect disposed about the same fivefold axis as the $\mathrm{Ag}_{54}$ core and the opposing $\mathrm{Ag}_{30}$ unit lies in an eclipsed configuration about the fivefold core aspect. With each apical pentagon surmounted by a $\mathrm{Cl}^{-}$anion, each of the other distorted pentagonal $\mathrm{Ag}_{5}$ and tetragonal $\mathrm{Ag}_{4}$ faces is capped by a thiolate ligand. The equatorial pentagon of the $\mathrm{Ag}_{54}$ core is encircled by a $\mathrm{Ag}-\mathrm{SR}$ complex ring. Four of the equatorial corners are spanned 


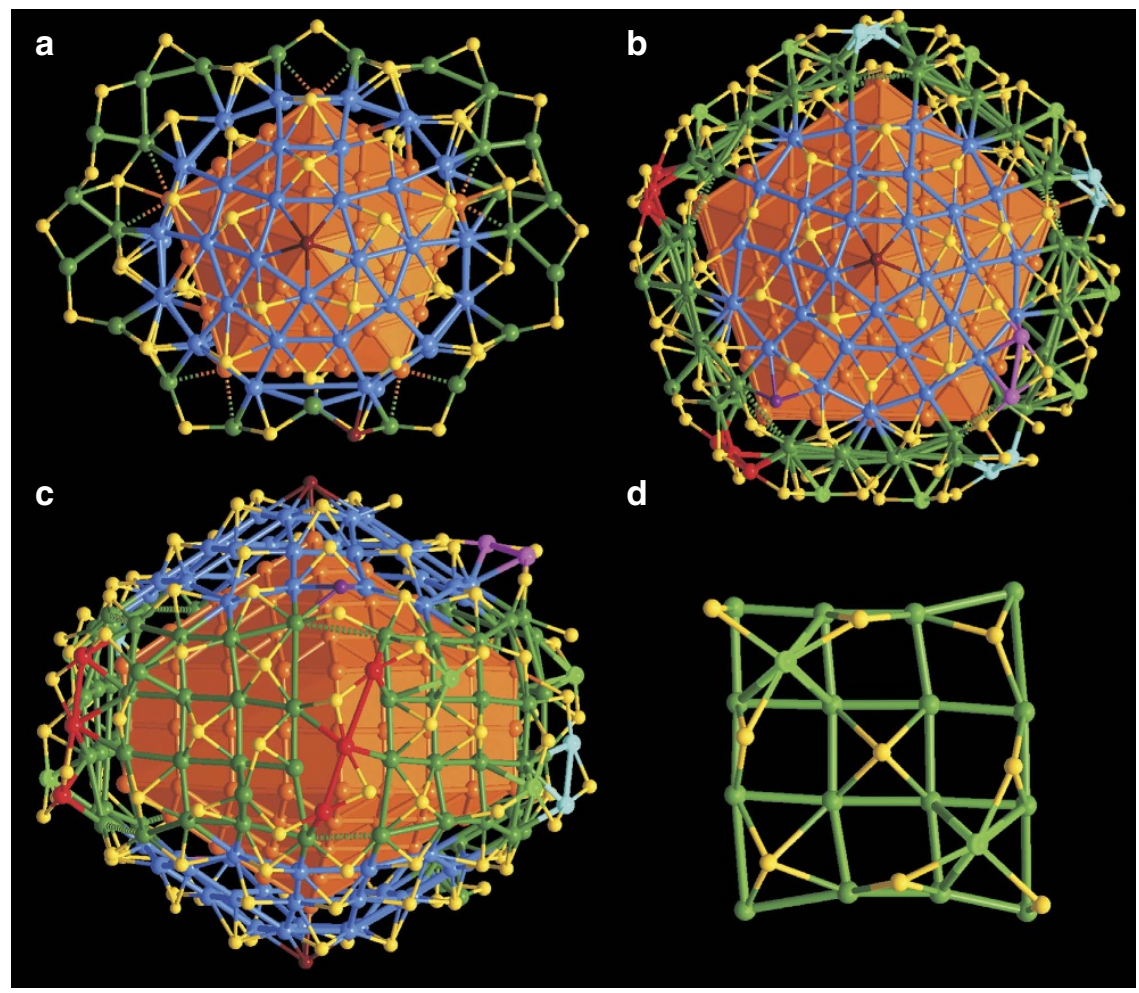

Figure 4 | The surface structures of $\mathbf{A g}_{\mathbf{1 3 6}}$ and $\mathbf{A g}_{\mathbf{3 7 4}}$ nanoparticles. (a) Top view of the complex shell of $\mathrm{Ag}_{136}$ with the bowl-like half $\mathrm{J} 73$ related $\left[\mathrm{Ag}_{30}(\mathrm{SR})_{15} \mathrm{Cl}\right]$ caps highlighted in blue. (b,c) Top and side views of the complex shell of $\mathrm{Ag}_{374}$ with key structure elements highlighted in different colours. (d) Representative $4 \times 4$ arrangement of surface $\mathrm{Ag}$ atoms on (100) side surface of the $\mathrm{Ag}_{207}$ core. Colour legend: yellow sphere, S; brown sphere, halogen; the rest, $\mathrm{Ag}$.

by one of four $\mathrm{Ag}_{2}(\mathrm{SR})_{5}$ units and the remaining corner is spanned by one $\mathrm{Ag}_{2}(\mathrm{SR})_{4} \mathrm{Cl}$ unit (against which the $\mathrm{PPh}_{4}^{+}$counterion rests). Detailed geometric analysis reveals that two significantly larger Ag-SR-Ag bond angles $\left(135.8(4)^{\circ}\right.$ and $\left.134.2(8)^{\circ}\right)$ occur within these units than in the remainder $\left(107.1(7)^{\circ}, 108.5(3)^{\circ}\right.$ and 105.8(5) ${ }^{\circ}$ for $\mathrm{Ag}_{2}(\mathrm{SR})_{4} \mathrm{Cl}$; Supplementary Fig. 16). Each of those with the larger Ag-SR-Ag bond angles is further spanned by $\mathrm{Ag}_{6}(\mathrm{SR})_{5}$ units. These units connect via $\mathrm{Ag}$ and $\mathrm{S}$ to the units they span and bridge via their Ag termini between the two smaller angle $\mathrm{Ag}_{2}(\mathrm{SR})_{5}$ and $\mathrm{Ag}_{2}(\mathrm{SR})_{4} \mathrm{Cl}$ completing the outer $\mathrm{AgS}$ layer.

In a strikingly similar manner, the fivefold twinned $\mathrm{Ag}_{207}$ core of $\mathrm{Ag}_{374}$ is also fully encapsulated by a complex Ag-thiolate layer. As shown in Fig. 4b, each pentagonal pyramid is analogously capped by a bowl-like $\left[\mathrm{Ag}_{30}(\mathrm{SR})_{15} \mathrm{Br}\right]$ of similar half $\mathrm{J73}$ configuration with the apical pentagonal sites occupied by bromide. The five side (100) faces of the $\mathrm{Ag}_{207}$ core are each covered by five near planar $\mathrm{Ag}_{16}$ units. In each $\mathrm{Ag}_{16}$ unit, the silver atoms are arranged in somewhat irregular $4 \times 4$ patterns (Fig. $4 \mathrm{c}, \mathrm{d}$ ). The atoms in each $\mathrm{Ag}_{16}$ unit are face-capped by three SR and two $\operatorname{Ag}(\mathrm{SR})_{3}$ motifs (Supplementary Fig. 17). At the five pentagonal prismatic edges of the $\mathrm{Ag}_{207}$ core, the $\mathrm{Ag}_{16}$ units are joined together by three $\mathrm{Ag}_{3}(\mathrm{SR})_{2}$, two $\mathrm{Ag}_{2}(\mathrm{SR})_{2}$ motifs and four bridging SR, forming a drum-like layer surrounding the elongated pentagonal prismatic equatorial aspect of the core. This drum-like layer connects the two bowl-like $\left[\mathrm{Ag}_{30}(\mathrm{SR})_{15} \mathrm{Br}\right]$ units via shared thiolates of the drum and a further two groups of $\mathrm{Ag}_{2}(\mathrm{SR})_{2}$ motifs, and ten bridging SR and one $\mathrm{Cl}$, which completes the closed complex shell having an overall composition of $\left[\mathrm{Ag}_{167}(\mathrm{SR})_{113} \mathrm{Cl}_{2} \mathrm{Br}_{2}\right]$ (Supplementary Fig. 18) surrounding the $\mathrm{Ag}_{207}$ core. For both $\mathrm{Ag}_{136}$ and $\mathrm{Ag}_{374}$, the $\mathrm{Ag}_{30}$ half-J73 domes lie with their apical pentagons eclipsed rather than staggered (as occurs in a complete 60 vertex J73 figure).
Electronic structures and optical properties. Both thiolated $\mathrm{Ag}_{136}$ and $\mathrm{Ag}_{374}$ nanoparticles are readily dissolved in solvents such as chloroform and dichloromethane, to give brown solutions. As shown in Fig. 5a,b, the smaller $\mathrm{Ag}_{136}$ nanoparticles display a broad major peak centred around $450 \mathrm{~nm}(2.75 \mathrm{eV})$ and a weak shoulder peak at $772 \mathrm{~nm}$, whereas the larger $\operatorname{Ag}_{374}$ nanoparticles show only one strong peak at $465 \mathrm{~nm}(2.67 \mathrm{eV})$. The $\mathrm{Ag}_{374}$ absorption behaviour is distinct from the molecule-like multiband absorption features of previously reported thiolated $\mathrm{Ag}$ nanoclusters (for instance, $\mathrm{Ag}_{14}, \mathrm{Ag}_{16}, \mathrm{Ag}_{25}, \mathrm{Ag}_{32}$ and $\left.\mathrm{Ag}_{44}\right)^{22,23,46-50}$ and that of $\mathrm{Ag}_{136}$.

The electronic structures of $\mathrm{Ag}_{136}$ and $\mathrm{Ag}_{374}$ were probed via DFT computations, by using the simplified SPh ligand in place of $\mathrm{SPh}-\mathrm{Bu}$ for $\mathrm{Ag}_{136}$ with a further simplification to $\mathrm{SH}$ for $\mathrm{Ag}_{374}$. The projected densities of electron states of the clusters are shown in Fig. 5c and Supplementary Fig. 19. The calculated highest occupied molecular orbital-lowest unoccupied molecular orbital band gap for $\mathrm{Ag}_{136}$ is $0.37 \mathrm{eV}$, whereas the band gap is closed for $\mathrm{Ag}_{374}$. The calculated band gap and angular momentum characteristics of the frontier orbitals (Supplementary Fig. 20) place $\mathrm{Ag}_{136}$ as a molecular system, whereas the $\mathrm{Ag}_{374}$ can be characterized as metallic.

The optical absorption of the $\mathrm{Ag}_{136}$ cluster was studied by using linear-response (LR) time-dependent DFT calculations. The optical spectrum of the atomistic model for $\mathrm{Ag}_{136}$ agrees very well with the experimental data, having an overall similar shape in the ultravioletvisible region and featuring a broad peak at $425 \mathrm{~nm}(2.9 \mathrm{eV}$; Fig. 5a and Supplementary Fig. 21). Analysis of this peak (Fig. 6) shows that it is composed of several contributions including $\operatorname{Ag}(5 s)$ to ligand, ligand to $\operatorname{Ag}(5 s)$, ligand to ligand and $\operatorname{Ag}(4 d)$ to $\operatorname{Ag}(5 s)$ transitions. The total transition induced density shows a collective dipole oscillation localized across the interface of the metal core with the 

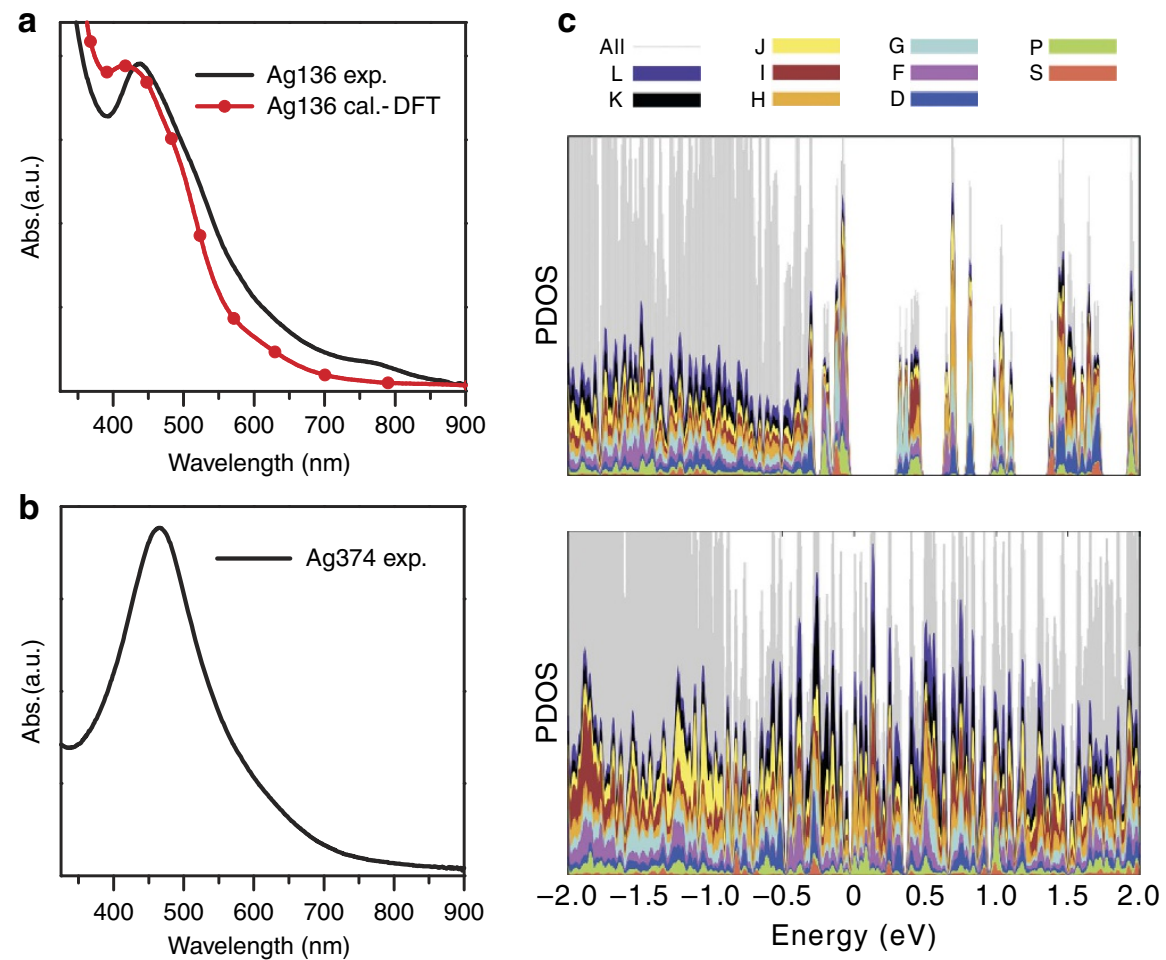

Figure 5 | Optical properties and electronic structures of $\mathbf{A g}_{\mathbf{1 3 6}}$ and $\mathbf{A g}_{\mathbf{3 7 4}}$ nanoparticles. (a,b) Ultraviolet-visible absorption spectra of (c) $\mathrm{Ag} 136$ (experimental and computed) and (b) $\mathrm{Ag}_{374}$ (experimental) nanoparticles. In the calculated spectra, the individual transitions are smoothed by using a Gaussian width of $0.1 \mathrm{eV}$. (c) Projection of the Kohn-Sham electron states (projected densities of electron states (PDOS)) of $\mathrm{Ag}_{136}$ (top) and $\mathrm{Ag}_{374}$ (bottom) to spherical harmonics centred at the metal core. The different spherical harmonics components $(S, P, D, \ldots)$ are indicated with colours as shown in the legend. The Fermi energy is at zero.
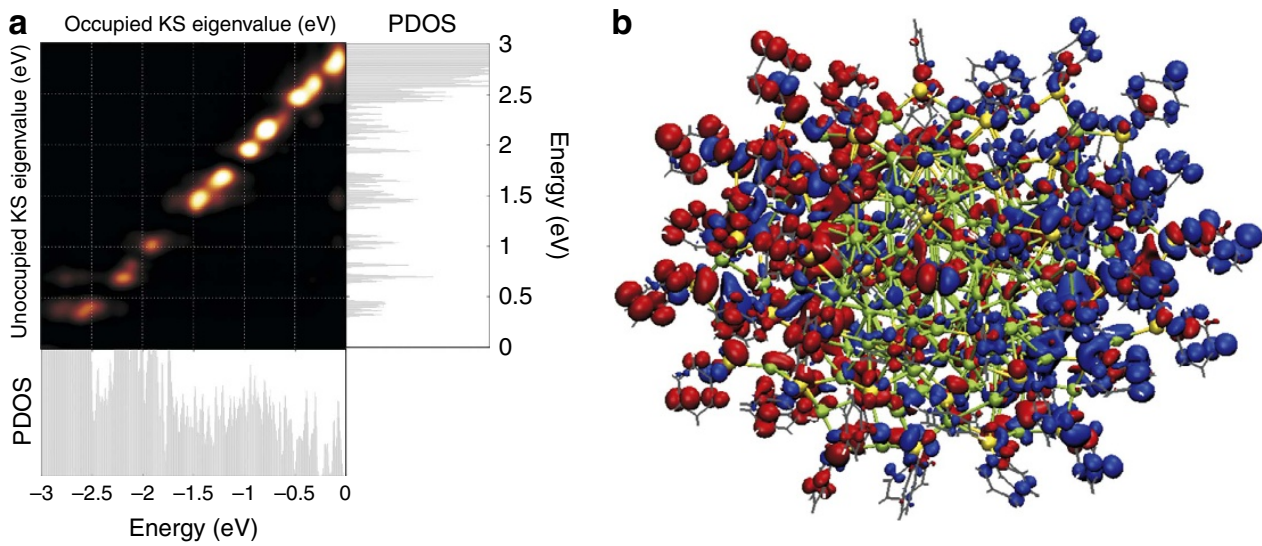

Figure 6 | Analysis of the peak at $425 \mathrm{~nm}(2.9 \mathrm{eV})$ in the time-dependent DFT (TDDFT) optical spectrum of $\mathbf{A g}_{136^{*}}$ (a) The transition contribution map shown on the top left reveals that this peak consists of a large number of single-electron particle-hole transitions. Holes are created for states from the Fermi level down to about $-2.5 \mathrm{eV}$ (horizontal projected densities of electron states (PDOS) plot) and particles are created for states from the lowest unoccupied molecular orbital (LUMO) state up to $\sim 2.9 \mathrm{eV}$ (vertical PDOS plot). In that energy range, both silver core states and ligand (sulfur and the pi-system of the phenyl) states are active and the total transition is a mixture of $\mathrm{Ag}(5 \mathrm{~s})$ to ligand, ligand to $\mathrm{Ag}(5 \mathrm{~s})$, ligand to ligand and $\mathrm{Ag}(4 \mathrm{~d})$ to $\mathrm{Ag}(5 \mathrm{~s})$ contributions. (b) The induced transition density shows the collective dipole oscillation. Blue and red colours indicate mean deficit and surplus of electron density, respectively.

ligand layer. We interpret this as a plasmonic feature where the pielectron density of the electron-rich ligand layer contributes to the collective oscillation. Based on this information, we interpret the experimental peak of $\mathrm{Ag}_{374}$ at $465 \mathrm{~nm}$ as of similar origin, where the slight red shift compared with the experimental peak of $\mathrm{Ag}_{136}$ is attributed to the much larger size of the system.

\section{Discussion}

This report demonstrates that it is feasible to deliberately and reproducibly synthesize metal nanoparticles with specific molecular products that readily enter the truly metallic regime with the emergence of SPR. As miniatures of fivefold twinned nanostructures of fcc metals, the success in resolving the total structures of $\mathrm{Ag}_{136}$ and $\mathrm{Ag}_{374}$ nanoparticles using single-crystal $\mathrm{X}$-ray diffraction provides important models to visualize at the atomic scale the modest distortion from ideality inside fivefold twinned nanostructures of fcc metals and to describe their detailed surface structures. The Ag nanoparticles reported in this work have the lowest size for silver to display surface plasmonic properties reported to date. These structures serve as real models 
to understand how silver nanoparticles can span from the molecular to the metallic regime.

The observed plasmonic peaks of $\mathrm{Ag}_{136}$ and $\mathrm{Ag}_{374}$ are below the threshold energy of the well-known Mie plasmon of $3.5 \mathrm{eV}$ for silver (dipolar bulk limit) ${ }^{51}$. In several gas phase, matrix isolation and surface studies in the past, atomic silver clusters from hundreds of atoms down to a few atoms exhibit resonance absorption at energies that are well over the Mie energy ${ }^{34,52}$. The fact that the thiol-stabilized $\mathrm{Ag}_{136}$ and $\mathrm{Ag}_{374}$ support an even lower bulk limit for the SPR, compared with the classical Mie energy for silver, is a manifestation of the important role played by the interfacial interactions between the thiolate layer and the nanoparticulate metal core. This clearly demonstrates that modifying the interface chemistry by introducing an organic passivating layer that has electronic properties distinct from thiolates could modify the plasmonic behaviour of ligandstabilized silver nanoparticles. Changes in the interfacial chemistry may provide scope to vary the adjustments in the core and the interfacial structure as well, opening a range of chemical possibilities through which nanoparticle structures and electronic properties can potentially be modified.

\section{Methods}

Synthesis of the Ag-SPhtBu complex precursor. The complex precursor was prepared by following the reported procedure ${ }^{53}$. In a typical synthesis, $4-t \mathrm{BuPhSH}$ $(0.38 \mathrm{ml}, 2.3 \mathrm{mmol})$ and $\mathrm{NEt}_{3}(0.32 \mathrm{ml}, 2.3 \mathrm{mmol})$ were mixed together in $8 \mathrm{ml}$ $\mathrm{C}_{2} \mathrm{H}_{5} \mathrm{OH}$. The mixture was then added dropwise to a solution of $\mathrm{AgNO}_{3}(274 \mathrm{mg}$, $1.6 \mathrm{mmol}$ ) in $5 \mathrm{ml} \mathrm{CH} \mathrm{CH}_{3} \mathrm{CN}$ under stirring. The mixture became a clear yellow solution on stirring overnight at room temperature under a nitrogen atmosphere. The yellow solution was dried under vacuum, to remove solvent yielding a yellow powder of the polymeric Ag-SPh $t \mathrm{Bu}$ precursor, $\left\{\left(\mathrm{HNEt}_{3}\right)_{2}\left[\mathrm{Ag}_{10}(\mathrm{SPh} t \mathrm{Bu})_{12}\right]\right\}_{n}$. This was stored in the dark under ambient conditions and used as the precursor for the syntheses of $\mathrm{Ag}_{136}$ and $\mathrm{Ag}_{374}$ nanoparticles.

Synthesis and crystallization of $\mathbf{A g}_{\mathbf{1 3 6}}$ nanoparticles. Thirty mlligrams of the $\mathrm{Ag}-\mathrm{SPh} t \mathrm{Bu}$ precursor (containing $92 \mu \mathrm{mol} \mathrm{Ag}$ and $110 \mu \mathrm{mol} \mathrm{SPh} t \mathrm{Bu}^{-}$based on the formula of $\left.\left\{\left(\mathrm{HNEt}_{3}\right)_{2}\left[\mathrm{Ag}_{10}(\mathrm{SPh} t \mathrm{Bu})_{12}\right]\right\}_{n}\right)$ were added to a mixed solvent of dichloromethane and methanol in a volume ratio of $4: 1$. The solution was cooled to $0{ }^{\circ} \mathrm{C}$ in an ice bath and $12 \mathrm{mg} \mathrm{PPh}_{4} \mathrm{Br}(29 \mu \mathrm{mol})$ was added to the solution. After $5 \mathrm{~min}$ stirring, $1 \mathrm{ml} \mathrm{NaBH}_{4}$ aqueous solution $\left(45 \mathrm{mg} \mathrm{ml}^{-1}, 1.2 \mathrm{mmol}\right.$ ) and $50 \mu \mathrm{l}$ triethylamine $(360 \mu \mathrm{mol})$ were added quickly under vigorous stirring. The reaction was aged for $12 \mathrm{~h}$ at $0^{\circ} \mathrm{C}$. The aqueous phase was removed and the organic phase was washed several times with water. The solvent was then evaporated to give a dark solid. Black prism-like crystals were crystallized from $\mathrm{CH}_{2} \mathrm{Cl}_{2} /$ hexane after 20 days at $4{ }^{\circ} \mathrm{C}$. The synthesis of $\mathrm{Ag}_{136}$ with the substitution of $\mathrm{Ph}_{4} \mathrm{PBr}$ by an equivalent of $\mathrm{Ph}_{4} \mathrm{PCl}$ also results in $\mathrm{Ag}_{136}$

Synthesis and crystallization of $\mathbf{A g}_{\mathbf{3 7 4}}$ nanoparticles. Thirty milligrams of the $\mathrm{Ag}-\mathrm{SPh} t \mathrm{Bu}$ precursor were added to a mixed solvent of dichloromethane and methanol. Twelve milligrams of $\mathrm{AgBF}_{4}(62 \mu \mathrm{mol})$ and $12 \mathrm{mg} \mathrm{PPh} \mathrm{Pr}_{4}(29 \mu \mathrm{mol})$ were added sequentially. After $5 \mathrm{~min}$ stirring, $1 \mathrm{ml} \mathrm{NaBH}$ aqueous solution $\left(45 \mathrm{mg} \mathrm{ml}^{-1}, 1.2 \mathrm{mmol}\right)$ and $50 \mu \mathrm{l}$ triethylamine $(360 \mu \mathrm{mol})$ were added quickly under vigorous stirring. The reaction was aged for $4 \mathrm{~h}$ at room temperature. The aqueous phase was discarded and the mixture in organic phase was washed several times with water and evaporated to give a dark solid. Black block-like crystals were crystallized from $\mathrm{CH}_{2} \mathrm{Cl}_{2}$ /hexane after 2 months at $4{ }^{\circ} \mathrm{C}$.

X-ray single-crystal analysis. Diffraction data of the single crystals grown from the solutions of $\mathrm{Ag}_{136}$ and $\mathrm{Ag}_{374}$ nanoparticles were collected on an Agilent Technologies SuperNova system X-ray single-crystal diffractometer with $\mathrm{Cu} \mathrm{K} \alpha$ radiation $(\lambda=1.54184 \AA)$ at $100 \mathrm{~K}$ to a resolution of $1.2 \AA$. The data were reduced using CrysAlis ${ }^{\text {Pro }}$. The structures were solved in ShelXL and refined using a combination of ShelXT, Olex2, Shelxle and CRYSTALS ${ }^{37-42}$. A customized refinement procedure employing techniques from both chemical crystallographic practice and macromolecular modelling methods (including contoured electron density mapping of all $t \mathrm{BuPh}$ groups) was evolved to address the challenges of each structure. In $\mathrm{Ag}_{136}$, a silver site of less than half occupancy has been modelled, which may be occupied in some molecules. The associated electron density refines well on this basis and the assignment makes chemical sense, noting that a sulfur atom with a high displacement parameter lies closer to this site than is reasonable. It is proposed that when this additional silver is present, the close sulfur atom lies in a site at the end of the sulfur ellipsoid furthest from the silver site. Significant 'solvent voids' are noted and it is proposed that these regions are more properly termed 'frozen solution' than solvent of crystallization in view of the very limited localized electron density features lying in the voids (note $\mathrm{CH}_{2} \mathrm{Cl}_{2}$ is the main solvent). The modest observed residual electron densities lie within the silver nanoparticles. No modifications to the data or refinement were made to account for these void volumes (see Supplementary Discussion and Supplementary Methods for further crystallographic details).

Computational method. The electronic structures of $\mathrm{Ag}_{136}$ and $\mathrm{Ag}_{374}$ were studied by DFT code GPAW, which implements projector-augmented wave method in a real-space grid ${ }^{54}$. The real space had a grid spacing of $0.2 \mathrm{~A}^{\circ} . \operatorname{Ag}\left(4 d^{10} 5 s^{1}\right)$, $\mathrm{S}\left(3 s^{2} 3 p^{4}\right), \operatorname{Br}\left(4 s^{2} 4 p^{5}\right)$ and $\mathrm{H}\left(1 s^{1}\right)$ electrons were regarded as the valence, and the projector-augmented wave setups for Ag included scalar-relativistic corrections. Structures and total energies were evaluated at the gradient-corrected functional of Perdew, Burke and Ernzerhof (PBE) level ${ }^{55}$. It should be pointed out that the configurations for $\mathrm{Ag}_{136}$ and $\mathrm{Ag}_{374}$ used in the calculations were taken from our preliminary crystallographic model. This $\mathrm{Ag}_{136}$ model had a formula of $\left[\mathrm{Ag}_{136}(\mathrm{SPh} t \mathrm{Bu})_{65} \mathrm{Br}_{2}\right]^{-}$which had 70 metallic free electrons (from the superatom counting rules). The electron number was same as that for the dominant final refined structure $\left[\mathrm{Ag}_{136}(\mathrm{SPh})_{64} \mathrm{Cl}_{3}\right]^{-}$. The correction to the structural formula for $\mathrm{Ag}_{136}$ does not affect our conclusions concerning the electronic structure and optical properties. The preliminary crystallographic model for $\mathrm{Ag}_{374}$ had a formula of $\left[\mathrm{Ag}_{374}(\mathrm{SR})_{115} \mathrm{Br}_{2}\right]$ containing two more $\mathrm{SR}^{-}$groups than that of the final refined structure again. These two sites were ultimately modelled with $\mathrm{Cl}$ at the former $\mathrm{S}$ site, yielding the same electron count. The organic groups were replaced by SPh for $\mathrm{Ag}_{136}$, after which the organic layer was relaxed to an energy minimum, while keeping the $\mathrm{Ag}, \mathrm{S}$ and $\mathrm{Br}$ atoms fixed to experimental positions. For $\mathrm{Ag}_{374}$, a simplified ligand $\mathrm{SR}=\mathrm{SH}$ was used and the $\mathrm{S}-\mathrm{H}$ bonds were relaxed, while keeping $\mathrm{Ag}, \mathrm{S}$ and $\mathrm{Br}$ atoms fixed to their experimental positions. Angular momentum analysis of the Kohn-Sham orbitals was done as metal-core projected density of states as described earlier ${ }^{56}$.

The optical absorption spectrum of $\mathrm{Ag}_{136}$ was calculated with the PBE level using time-dependent DFT formalism in GPAW. ${ }^{57}$ The grid spacing was $0.8 \AA$ The electron density and wave functions were calculated by the local density approximation and the PBE functional was used for calculating LR optical absorption spectra. The transitions contributing to selected optical peaks were analysed using a recently developed method based on time-dependent density functional perturbation theory ${ }^{58}$.

Data availability. The X-ray crystallographic coordinates for structures reported in this article have been deposited at the Cambridge Crystallographic Data Centre, under deposition number CCDC-1496141 $\left(\mathrm{Ag}_{374}\right)$ and $1496142\left(\mathrm{Ag}_{136}\right)$. These data can be obtained free of charge from the Cambridge Crystallographic Data Centre via www.ccdc.cam.ac.uk/data_request/cif. All other data are available from the authors on reasonable request.

\section{References}

1. Alivisatos, A. P. Semiconductor clusters, nanocrystals, and quantum dots. Science 271, 933-937 (1996).

2. Daniel, M.-C. \& Astruc, D. Gold nanoparticles: assembly, supramolecular chemistry, quantum-size-related properties, and applications toward biology, catalysis, and nanotechnology. Chem. Rev. 104, 293-346 (2004).

3. Volokitin, Y. et al. Quantum-size effects in the thermodynamic properties of metallic nanoparticles. Nature 384, 621-623 (1996).

4. Collier, C. P., Saykally, R. J., Shiang, J. J., Henrichs, S. E. \& Heath, J. R. Reversible tuning of silver quantum dot monolayers through the metalinsulator transition. Science 277, 1978-1981 (1997).

5. Anker, J. N. et al. Biosensing with plasmonic nanosensors. Nat. Mater. 7, 442-453 (2008).

6. Dai, X. et al. Solution-processed, high-performance light-emitting diodes based on quantum dots. Nature 515, 96-99 (2014).

7. Michalet, X. et al. Quantum dots for live cells, in vivo imaging, and diagnostics. Science 307, 538-544 (2005).

8. Norris, D. J., Efros, A. L. \& Erwin, S. C. Doped nanocrystals. Science 319, 1776-1779 (2008).

9. Xia, Y., Xiong, Y., Lim, B. \& Skrabalak, S. E. Shape-controlled synthesis of metal nanocrystals: simple chemistry meets complex physics? Angew. Chem. Int. Ed. 48, 60-103 (2009)

10. Qu, L. \& Peng, X. Control of photoluminescence properties of CdSe nanocrystals in growth. J. Am. Chem. Soc. 124, 2049-2055 (2002).

11. Puntes, V. F., Krishnan, K. M. \& Alivisatos, A. P. Colloidal nanocrystal shape and size control: the case of cobalt. Science 291, 2115-2117 (2001).

12. Scott, M. C. et al. Electron tomography at 2.4-angstrom resolution. Nature 483, 444-447 (2012).

13. Li, Z. Y. et al. Three-dimensional atomic-scale structure of size-selected gold nanoclusters. Nature 451, 46-48 (2008).

14. Van Aert, S., Batenburg, K. J., Rossell, M. D., Erni, R. \& Van Tendeloo, G. Three-dimensional atomic imaging of crystalline nanoparticles. Nature 470, 374-377 (2011). 
15. Chen, C. -C. et al. Three-dimensional imaging of dislocations in a nanoparticle at atomic resolution. Nature 496, 74-77 (2013).

16. Azubel, M. et al. Electron microscopy of gold nanoparticles at atomic resolution. Science 345, 909-912 (2014)

17. Johnson, C. L. et al. Effects of elastic anisotropy on strain distributions in decahedral gold nanoparticles. Nat. Mater. 7, 120-124 (2008).

18. Tran, N. T., Powell, D. R. \& Dahl, L. F. Nanosized $\mathrm{Pd}_{145}(\mathrm{CO})_{\mathrm{x}}\left(\mathrm{PEt}_{3}\right)_{30}$ containing a capped three-shell 145-atom metal-core geometry of pseudo icosahedral symmetry. Angew. Chem. Int. Ed. 39, 4121-4125 (2000).

19. Jadzinsky, P. D., Calero, G., Ackerson, C. J., Bushnell, D. A. \& Kornberg, R. D. Structure of a thiol monolayer-protected gold nanoparticle at $1.1 \AA$ resolution. Science 318, 430-433 (2007).

20. Zeng, C. et al. Structural patterns at all scales in a nonmetallic chiral $\mathrm{Au}_{133}(\mathrm{SR})_{52}$ nanoparticle. Sci. Adv. 1, e1500045 (( (2015).

21. Dass, A. et al. $\mathrm{Au}_{133}(\mathrm{SPh}-\mathrm{tBu})_{52}$ nanomolecules: $\mathrm{x}$-ray crystallography, optical, electrochemical, and theoretical analysis. J. Am. Chem. Soc. 137, 4610-4613 (2015).

22. Yang, H. Y. et al. All-thiol-stabilized $\mathrm{Ag}_{44}$ and $\mathrm{Au}_{12} \mathrm{Ag}_{32}$ nanoparticles with single-crystal structures. Nat. Commun. 4, 2422 (2013).

23. Desireddy, A. et al. Ultrastable silver nanoparticles. Nature 501, 399-402 (2013).

24. Zeng, C. et al. Total structure and electronic properties of the gold nanocrystal $\mathrm{Au}_{36}(\mathrm{SR})_{24}$. Angew. Chem. Int. Ed. 51, 13114-13118 (2012).

25. Crasto, D. et al. $\mathrm{Au}_{24}(\mathrm{SAdm})_{16}$ nanomolecules: $\mathrm{x}$-ray crystal structure, theoretical analysis, adaptability of adamantane ligands to form $\mathrm{Au}_{23}(\mathrm{SAdm})_{16}$ and $\mathrm{Au}_{25}(\mathrm{SAdm})_{16}$, and its relation to $\mathrm{Au}_{25}(\mathrm{SR})_{18}$. J. Am. Chem. Soc. 136, 14933-14940 (2014).

26. Crasto, D., Malola, S., Brosofsky, G., Dass, A. \& Häkkinen, H. Single crystal $\mathrm{XRD}$ structure and theoretical analysis of the chiral Au30S(S-t-Bu)18 cluster. J. Am. Chem. Soc. 136, 5000-5005 (2014).

27. Das, A. et al. Total structure and optical properties of a phosphine/thiolateprotected Au-24 nanocluster. J. Am. Chem. Soc. 134, 20286-20289 (2012).

28. Heaven, M. W., Dass, A., White, P. S., Holt, K. M. \& Murray, R. W. Crystal structure of the gold nanoparticle $\left[\mathrm{N}\left(\mathrm{C}_{8} \mathrm{H}_{17}\right)_{4}\right]\left[\mathrm{Au}_{25}\left(\mathrm{SCH}_{2} \mathrm{CH}_{2} \mathrm{Ph}\right)_{18}\right]$. J. Am. Chem. Soc. 130, 3754-3755 (2008).

29. Qian, H. F., Eckenhoff, W. T., Zhu, Y., Pintauer, T. \& Jin, R. C. Total structure determination of thiolate-protected $\mathrm{Au}_{38}$ nanoparticles. J. Am. Chem. Soc. 132, 8280-8281 (2010).

30. Zeng, C. J., Li, T., Das, A., Rosi, N. L. \& Jin, R. C. Chiral structure of thiolateprotected 28-gold-atom nanocluster determined by X-ray crystallography. J. Am. Chem. Soc. 135, 10011-10013 (2013).

31. Zhu, M. Z., Aikens, C. M., Hollander, F. J., Schatz, G. C. \& Jin, R. Correlating the crystal structure of a thiol-protected $\mathrm{Au}_{25}$ cluster and optical properties. J. Am. Chem. Soc. 130, 5883-5885 (2008).

32. Chen, Y. et al. Crystal structure of barrel-shaped chiral $A_{130}(\mathrm{p}-\mathrm{MBT})_{50}$ nanocluster. J. Am. Chem. Soc. 137, 10076-10079 (2015).

33. Qian, H., Zhu, Y. \& Jin, R. Atomically precise gold nanocrystal molecules with surface plasmon resonance. Proc. Natl Acad. Sci. USA 109, 696-700 (2012).

34. Scholl, J. A., Koh, A. L. \& Dionne, J. A. Quantum plasmon resonances of individual metallic nanoparticles. Nature 483, 421-427 (2012).

35. Gryaznov, V. G. et al. Pentagonal symmetry and disclinations in small particles. Cryst. Res. Technol. 34, 1091-1119 (1999).

36. Hofmeister, H. Forty years study of fivefold twinned structures in small particles and thin films. Cryst. Res. Technol. 33, 3-25 (1998).

37. Sheldrick, G. A short history of SHELX. Acta Cryst. A 64, 112-122 (2008).

38. Sheldrick, G. SHELXT- Integrated space-group and crystal-structure determination. Acta Cryst. A 71, 3-8 (2015).

39. Betteridge, P. W., Carruthers, J. R., Cooper, R. I., Prout, K. \& Watkin, D. J. CRYSTALS version 12: software for guided crystal structure analysis. J. Appl. Crystallogr. 36, 1487 (2003).

40. Cooper, R. I., Gould, R. O., Parsons, S. \& Watkin, D. J. The derivation of nonmerohedral twin laws during refinement by analysis of poorly fitting intensity data and the refinement of non-merohedrally twinned crystal structures in the program CRYSTALS. J. Appl. Crystallogr. 35, 168-174 (2002).

41. Dolomanov, O. V., Bourhis, L. J., Gildea, R. J., Howard, J. A. K. \& Puschmann, H. OLEX2: a complete structure solution, refinement and analysis program. J. Appl. Crystallogr. 42, 339-341 (2009).

42. Huebschle, C. B., Sheldrick, G. M. \& Dittrich, B. ShelXle: a Qt graphical user interface for SHELXL. J. Appl. Crystallogr. 44, 1281-1284 (2011).

43. Fenske, D. et al. Syntheses and crystal structures of $\left[\mathrm{Ag}_{123} \mathrm{~S}_{35}(\mathrm{StBu})_{50}\right]$ and $\left[\mathrm{Ag}_{344} \mathrm{~S}_{124}(\mathrm{StBu})_{96}\right]$. Angew. Chem. Int. Ed. 44, 5242-5246 (2005).

44. Anson, C. E. et al. Synthesis and crystal structures of the ligand-stabilized silver chalcogenide clusters $\left[\mathrm{Ag}_{154} \mathrm{Se}_{77}(\mathrm{dppxy})_{18}\right],\left[\mathrm{Ag}_{320}(\mathrm{StBu})_{60} \mathrm{~S}_{130}(\mathrm{dppp})_{12}\right]$, $\left[\mathrm{Ag}_{352} \mathrm{~S}_{128}\left(\mathrm{StC}_{5} \mathrm{H}_{11}\right)_{96}\right]$, and $\left[\mathrm{Ag}_{490} \mathrm{~S}_{188}\left(\mathrm{StC}_{5} \mathrm{H}_{11}\right)_{114}\right]$. Angew. Chem. Int. Ed. 47, 1326-1331 (2008).

45. Sau, T. K. \& Rogach, A. L. Nonspherical noble metal nanoparticles: colloidchemical synthesis and morphology control. Adv. Mater. 22, 1781-1804 (2010).
46. Bakr, O. M. et al. Silver nanoparticles with broad multiband linear optical absorption. Angew. Chem. Int. Ed. 48, 5921-5926 (2009).

47. Yang, H. Y. et al. Crystal structure of a luminescent thiolated Ag nanocluster with an octahedral $\mathrm{Ag}_{6}^{4+}$ core. Chem. Commun. 49, 300-302 (2013).

48. Yang, H. Y., Wang, Y. \& Zheng, N. F. Stabilizing subnanometer $\operatorname{Ag}(0)$ nanoclusters by thiolate and diphosphine ligands and their crystal structures. Nanoscale 5, 2674-2677 (2013).

49. Yan, J. Z. et al. Total structure and electronic structure analysis of doped thiolated silver $\left[\mathrm{MAg}_{24}(\mathrm{SR})_{18}\right]^{2-}(\mathrm{M}=\mathrm{Pd}, \mathrm{Pt})$ clusters. J. Am. Chem. Soc. 137, 11880-11883 (2015).

50. Joshi, C. P., Bootharaju, M. S., Alhilaly, M. J. \& Bakr, O. M. $\left[\operatorname{Ag}_{25}(\mathrm{SR})_{18}\right]^{-}$: the "golden" silver nanoparticle. J. Am. Chem. Soc. 137, 11578-11581 (2015).

51. Kreibig, U. \& Vollmer, M. Optical Properties of Metal Clusters (Springer, 1995).

52. Haberland, H. Looking from both sides. Nature 494, E1-E2 (2013).

53. Tang, K., Xie, X., Zhao, L., Zhang, Y. \& Jin, X. Synthesis and crystal structure of $\left\{\left[\mathrm{HNEt}_{3}\right]_{2 \mathrm{n}}\left[\mathrm{Ag}_{8} \mathrm{Ag}_{4 / 2}\left(\mathrm{SC}_{6} \mathrm{H}_{4} t \mathrm{Bu}-4\right)_{12}\right]_{\mathrm{n}} \cdot \mathrm{nC}_{2} \mathrm{H}_{5} \mathrm{OH}\right\}$ and its reaction product with $\mathrm{CS}_{2}$. Eur. J. Inorg. Chem. 2004, 78-85 (2004).

54. Enkovaara, J. et al. Electronic structure calculations with GPAW: a real-space implementation of the projector augmented-wave method. J. Phys. Condens. Matter 22, 253202 (2010).

55. Perdew, J. P., Burke, K. \& Ernzerhof, M. Generalized gradient approximation made simple. Phys. Rev. Lett. 77, 3865 (1996).

56. Walter, M. et al. A unified view of ligand-protected gold clusters as superatom complexes. Proc. Natl Acad. Sci. USA 105, 9157-9162 (2008).

57. Walter, M. et al. Time-dependent density-functional theory in the projector augmented-wave method. J. Chem. Phys. 128, 244101 (2008).

58. Malola, S., Lehtovaara, L., Enkovaara, J. \& Häkkinen, H. Birth of the localized surface plasmon resonance in monolayer-protected gold nanoclusters. ACS Nano 7, 10263-10270 (2013)

\section{Acknowledgements}

N.F.Z acknowledges the financial support from the Ministry of Science and Technology of China (2015CB932303), and the National Nature Science Foundation of China (21420102001, 21131005, 21390390, 21227001 and 21333008). H.H. acknowledges funding from the Academy of Finland (266492) and B.D. acknowledges funding from the Deutsche Forschungsgemeinschaft within DI 921/6-1. D.D.W. acknowledges the financial support from the National Nature Science Foundation of China (11222221 and 11472233) and the Natural Science Foundation of Fujian Province of China (2014J06001). The computational resources were provided by CSC-the Finnish IT Center for Science. We thank Professor L.S. Zheng for helpful discussions and Drs Z.E. Yan and F. White for assistance with crystal structure solution. Brian McMahon and Mike Hoyland of the IUCr Chester Office are thanked for their assistance in processing the CIFs accompanying this article.

\section{Author contributions}

N.F.Z. designed the study, supervised the project and analysed data. Y.H.Y and Y.W conceived and carried out experiments and analysed the data. H.Q.H. and J.Z.Y. assisted in the synthesis of $\mathrm{Ag}_{374}$. TEM studies were done by X.J.Z. and L.G. G.L., C.F.X. and Z.C.T. carried out temperature-programmed decomposition/mass-spectrometric measurements. The geometric distortion analysis was done by J.C.W. and D.D.W. Y.H.Y conducted the experimental X-ray work structure solution and initial modelling, while A.J.E. and B.D. undertook the detailed crystallographic analysis. All computations and theoretical analyses were done by X.C., L.L. and H.H. All authors contributed to the preparation of the manuscript. H.Y.Y. and Y.W. equally contributed to this work.

\section{Additional information}

Supplementary Information accompanies this paper at http://www.nature.com/ naturecommunications

Competing financial interests: The authors declare no competing financial interests

Reprints and permission information is available online at http://npg.nature.com/ reprintsandpermissions/

How to cite this article: Yang, H. et al. Plasmonic twinned silver nanoparticles with molecular precision. Nat. Commun. 7:12809 doi: 10.1038/ncomms12809 (2016).

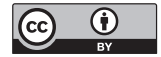

This work is licensed under a Creative Commons Attribution 4.0 International License. The images or other third party material in this article are included in the article's Creative Commons license, unless indicated otherwise in the credit line; if the material is not included under the Creative Commons license, users will need to obtain permission from the license holder to reproduce the material. To view a copy of this license, visit http://creativecommons.org/licenses/by/4.0/

(C) The Author(s) 2016 